\title{
Article
}

\section{Study on Prevention and Treatment Strategy of Asphalt Ultraviolet (UV) Aging Based on UV Climate Zoning in China}

\author{
Ling Zou ${ }^{1,2,3, * \mathbb{D}}$, Zhongbo Lou ${ }^{4}$, Minghui Li ${ }^{5}$, Honghua Xue ${ }^{2}$, Yu Chen ${ }^{6}$ and Wengang Zhang ${ }^{6,7} \mathbb{D}$ \\ 1 School of Transportation, Southeast University, Nanjing 211189, China \\ 2 CCCC First Highway Consultants Co., Ltd., Xi'an 710075, China; xuehonghuacccc@126.com \\ 3 School of Highway, Chang'an University, Xi'an 710064, China \\ 4 Tianjin Municipal Engineering Design and Research Institute Co., Ltd., Tianjin 300051, China; \\ louzhongbo0516@163.com \\ 5 Power China Northwest Engineering Corporation Limited, Xi'an 710065, China; ydlmh@sina.cn \\ 6 School of Civil and Architectural Engineering, Shandong University of Technology, Zibo 255049, China; \\ sdlgdxcy@163.com (Y.C.); ziwuzizwg@sdut.edu.cn (W.Z.) \\ 7 Key Laboratory of Transport Industry of Road Structure and Material, Research Institute of Highway, \\ Ministry of Transport, Beijing 100088, China \\ * Correspondence: zoulwelcme@163.com; Tel.: +86-88372356
}

Citation: Zou, L.; Lou, Z.; Li, M.; Xue, H.; Chen, Y.; Zhang, W. Study on Prevention and Treatment Strategy of Asphalt Ultraviolet (UV) Aging Based on UV Climate Zoning in China. Appl. Sci. 2021, 11, 6665. https://doi.org/ 10.3390/app11146665

Academic Editors: Cesare Oliviero Rossi and Luis Picado Santos

Received: 26 May 2021

Accepted: 19 July 2021

Published: 20 July 2021

Publisher's Note: MDPI stays neutral with regard to jurisdictional claims in published maps and institutional affiliations.

Copyright: (c) 2021 by the authors. Licensee MDPI, Basel, Switzerland. This article is an open access article distributed under the terms and conditions of the Creative Commons Attribution (CC BY) license (https:// creativecommons.org/licenses/by/ $4.0 /)$.

\begin{abstract}
The purpose of this paper, based on the amount of ultraviolet (UV) radiation in different areas of China, was to give the corresponding measures to prevent UV aging of asphalt. In this paper, based on the average annual amount of UV radiation in China in the past 30 years and the characteristics of UV aging of asphalt, the climatic zoning of UV radiation of asphalt in China was proposed. A variety of base asphalts and styrene-butadiene-styrene block copolymer (SBS) modified asphalts were selected to carry out a UV radiation test, and the relationship between UV radiation amount and viscosity, low-temperature performance, and the rheological properties of asphalt were studied. The equivalent aging indexes of asphalt during UV radiation were selected, the UV aging equation of asphalt was proposed, and the equivalent UV aging relationship among different UV climate zones was established. The prevention and control strategies of UV aging of asphalt among different zones were proposed, and the above theory was verified using a trial road. The main conclusions in the paper are presented: The climate zoning of asphalt UV radiation in China can be divided into three zones: zone I with an annual UV radiation less than or equal to $69.4 \mathrm{~kW} \cdot \mathrm{h} / \mathrm{m}^{2}$ in the last 30 years; zone II with an annual UV radiation of $69.4 \sim 81.4 \mathrm{~kW} \cdot \mathrm{h} / \mathrm{m}^{2}$ in the last 30 years; zone III with an annual UV radiation more than or equal to $81.4 \mathrm{~kW} \cdot \mathrm{h} / \mathrm{m}^{2}$ in the last 30 years. The greater the amount of UV radiation, the greater the loss rate of penetration and ductility. For the same kind of asphalt, there is a relatively stable functional relationship between the loss rate and the amount of UV radiation. The results also show that UV radiation changes the proportion of viscous and elastic components in asphalt, showing that the proportion of viscous components decreases and the proportion of elastic components increases. The penetration loss rate and ductility loss rate of asphalt can be used as equivalent UV aging indexes of asphalt. Under the same outdoor UV irradiation time, for asphalt to achieve the same technical performance as zone I, the anti-UV ability of zone II needs to be improved by more than $5 \%$, and that of zone III needs to be improved by more than $10 \%$. Engineering practice has proved that the zoning established in this paper and the corresponding UV control measures are basically reasonable.
\end{abstract}

Keywords: ultraviolet rays; ultraviolet climate zoning; asphalt; UV aging law; equivalent aging indexes of asphalt; prevention and control strategy

\section{Introduction}

The anti-aging performance of asphalt and asphalt mixture is an important factor affecting the service quality and service life of asphalt pavement. The aging process and 
degree of asphalt in different structural layers of asphalt surface course are quite different, among which the aging of upper layer asphalt is the most serious [1,2]. The external temperature and traffic load on the pavement can be shared by each structural layer of asphalt pavement, but solar radiation, as a natural energy source, can only be borne by the surface layer of asphalt pavement alone [3,4]. Although the direct effect of $\mathrm{UV}$ radiation is on the asphalt surface, considering the diffusion of asphalt molecules after aging and the existence of asphalt pavement voids, the actual effect of UV radiation on the asphalt surface can reach about $1 \mathrm{~cm}$ [5]. UV aging results in an increase in low-temperature stiffness of surface asphalt mixture, from which it is very easy to produce temperature shrinkage cracking, thus increasing the depth of UV incidence. Coupled with the influence of rain and snow, the pavement condition can further deteriorate, which seriously affects the durability of the pavement [6]. Therefore, the aging effect of asphalt pavement materials caused by UV radiation cannot be ignored.

UV aging is a type of long-term aging in the process of asphalt pavements. At present, the evaluation indexes and methods for the anti-UV aging performance of asphalt are mainly as follows:

- Evaluation method based on penetration, ductility, mass loss, and other indicators after UV aging [7-9];

- Evaluation method based on rheological property index [10-15];

- Evaluation method based on whole section fracture energy index [16,17];

- Evaluation method based on asphalt colloidal structure component index [18,19];

- Evaluation method based on molecular dynamics index [20].

UV aging has a significant effect on the physical and rheological properties of base asphalt and modified asphalt. The changes in asphalt components directly affect the physical properties of asphalt, and there is a good corresponding relationship between the proportion of soft and hard components and rheological indexes. The differences of chemical components in asphalt leads to different degrees of aging reaction. Aromatic components and gum are the main factors affecting the anti-ultraviolet aging ability of asphalt [21].

The impact of UV radiation on an asphalt pavement mainly occurs in the surface layer. Therefore, the anti-UV aging methods for asphalt pavements mainly focus on two aspects: one is to improve the anti-UV aging performance of asphalt materials [22-27], and the other is to pave, coat, or spray anti-UV aging materials on the upper layer of asphalt pavement, thus improving the anti-UV aging ability of the upper layer [28-34]. Studies have found that the UV aging mechanism of asphalt can be explained by the aging mechanism of polymer materials. Therefore, the anti-UV aging methods of polymer materials are also used for reference in the improvement of asphalt UV aging $[35,36]$.

High polymer materials usually add a certain amount of anti-aging agent to improve thermal-oxidative aging and UV aging, such as using $\mathrm{TiO} 2$ to improve the UV stability of PVC, adding light shield agent in PVC film to improve its UV aging resistance, or adding hindered amine light stabilizer and antioxidant to improve the UV stability of polymer [37-41]. At present, the research on the improvement measures of UV aging of asphalt is mainly focused on the anti-UV aging modification of asphalt materials.

There are great differences in the intensity of UV radiation in different areas. Therefore, it is important to choose the corresponding UV prevention and control measures according to the intensity of UV radiation. However, the UV aging of asphalt has not been included in the material design index in the relevant specifications of China, and the relevant researches are mostly carried out for local areas.

In a word, as far as China is concerned, there are still some problems in the research and prevention of asphalt UV aging.

- The influence of UV radiation on asphalt has not been expressed uniformly and clearly, and there is no standard test method for the UV aging of asphalt in the current specification;

- There is a lack of practical climate zoning for asphalt UV radiation;

- The equivalent relationship of asphalt UV aging between different UV radiation areas has not been established; 
- There is a lack of anti-UV aging prevention methods for asphalt in different UV radiation areas.

Therefore, it is urgent and meaningful to put forward the corresponding zoning for asphalt UV aging in China and the corresponding prevention measures and prevention standards for different zones. The purpose of this paper is to solve the above four problems, and then to achieve the climate zoning for asphalt UV radiation.

On the basis of the above research status, in order to provide reasonable prevention and control measures for asphalt UV aging in different areas of China, based on the average annual UV radiation amount in China in the most recent 30 years and the characteristics of asphalt UV aging, this paper puts forward the climatic zoning of asphalt UV radiation in China. A variety of base asphalts and styrene-butadiene-styrene block copolymer (SBS) modified asphalts were selected to carry out an UV radiation test, and the relationship between UV radiation amount and viscosity, low-temperature performance, and rheological properties of asphalt were studied. The equivalent aging indexes of asphalt during UV radiation were selected, the UV aging equation of asphalt was proposed, and the equivalent UV aging relationship among different UV climate zones was established. The prevention and control strategies of UV aging of asphalt among different zones was proposed, and the above theory was verified using a trial road. The research results can provide necessary technical support for improving the durability of asphalt pavements in China.

\section{Climate Zoning of Asphalt UV Radiation in China}

China is a vast country with uneven distribution of UV radiation. It is well known that UV radiation comes from sunlight. The duration of sunlight and the total amount of solar radiation play a decisive role in the amount of UV radiation. In addition, it is also related to the absorption of UV radiation by ozone in the atmosphere when sunlight passes through the atmosphere. Therefore, the distribution of UV rays in the territory of China is very complex due to the comprehensive effects of various factors. Figure 1 shows the distribution of average annual illumination duration in China in the most recent 30 years $[42,43]$.

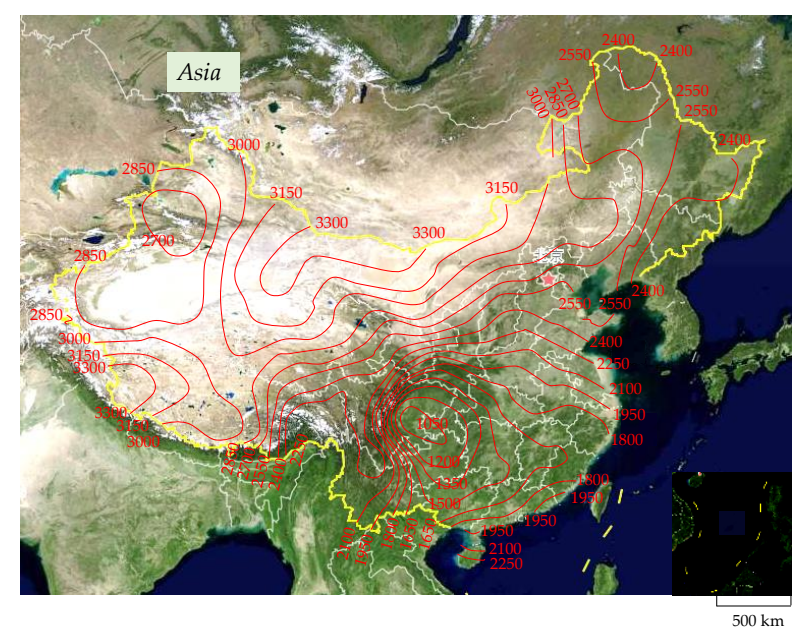

Figure 1. Distribution of annual average sunshine duration (h) in China from 1990 to 2020 [42,43].

The region with the shortest sunshine duration in China is in the Sichuan Basin, and the region with the longest sunshine duration is in the Qinghai-Tibet Plateau. The sunshine duration in the east is generally shorter than that in the northwest, but the sunshine duration is not equal to the distribution of solar energy resources and is also related to the climate conditions, such as cloud thickness. Figure 2 shows the distribution of annual total solar radiation in China in the most recent 30 years [42,43]. 


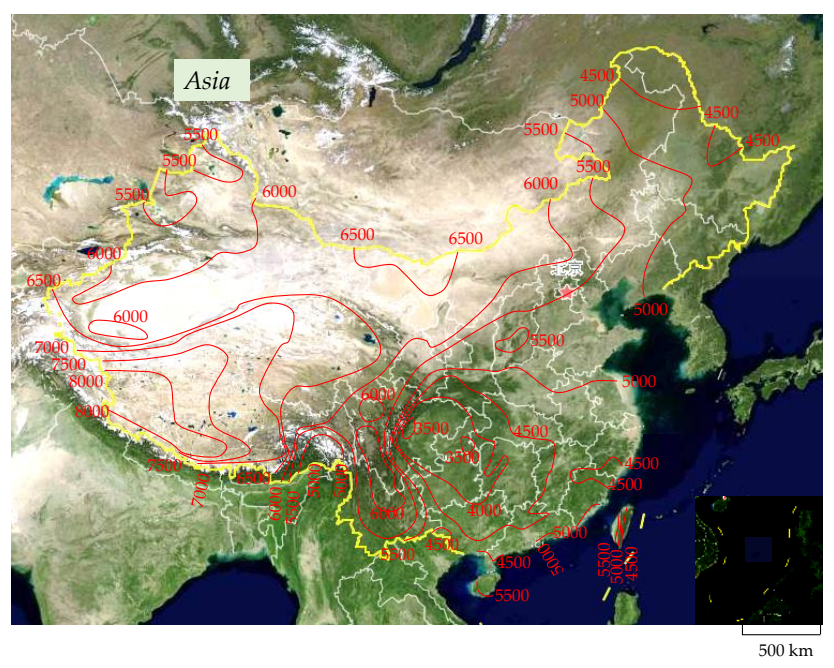

Figure 2. Distribution of annual total solar radiation $\left(\mathrm{MJ} / \mathrm{m}^{2}\right)$ in China from 1990 to 2020 [42,43].

Figure 2 shows that the distribution of solar radiation in China is closely related to the duration of sunshine. The Sichuan Basin is still a depression of solar radiation, while the Qinghai-Tibet Plateau is a highland of solar radiation. Except for the northwest of Xinjiang, the level of solar radiation increases gradually from the east to the west, and the northern region is generally greater than the southern region. This is contrary to the rule that solar energy changes with latitude, and the reason is due to there being more cloud and rainy weather in the south. The amount of UV radiation on the road generally accounts for $5 \sim 8 \%$ of the solar energy resources, and the proportion varies according to different climate conditions. The Wind and Solar Energy Resources Center of China divides China's UV radiation into five zones. According to the annual total amount of UV radiation, this is $334 \sim 420 \mathrm{MJ} / \mathrm{m}^{2}$ in zone 1, 293 334 MJ $/ \mathrm{m}^{2}$ in zone 2, 250 293 MJ/m² in zone 3, $210 \sim 250 \mathrm{MJ} / \mathrm{m}^{2}$ in zone 4 , and $167 \sim 210 \mathrm{MJ} / \mathrm{m}^{2}$ in zone 5 . Converted into $\mathrm{kwh} / \mathrm{m}^{2}$, this is $92.8 \sim 116.7 \mathrm{~kW} \cdot \mathrm{h} / \mathrm{m}^{2}$ for zone $1,81.4 \sim 92.8 \mathrm{~kW} \cdot \mathrm{h} / \mathrm{m}^{2}$ for zone $2,69.4 \sim 81.4 \mathrm{~kW} \cdot \mathrm{h} / \mathrm{m}^{2}$ for zone $3,58.4 \sim 69.4 \mathrm{~kW} \cdot \mathrm{h} / \mathrm{m}^{2}$ for zone 4 , and $46.4 \sim 58.4 \mathrm{~kW} \cdot \mathrm{h} / \mathrm{m}^{2}$ for zone 5 [42].

According to the law of the influence of UV radiation on asphalt aging performance, the effect of UV radiation on asphalt aging in zones four and five is not very different, so these are combined into one large area in this paper. In addition, since zone 1 and zone 2 occupy a small area, and these are located on the Inner Mongolia grassland and the Qinghai-Tibet Plateau, the population density of the above areas is relatively small, and the highway density is not large, so zone 1 and zone 2 are combined into a large UV irradiation zone in this paper. Based on the above principles, the climate zones of asphalt UV irradiation in China are proposed as:

Zone I: the annual UV radiation in the most recent 30 years is not more than or equal to $69.4 \mathrm{~kW} \cdot \mathrm{h} / \mathrm{m}^{2}$;

Zone II: the annual UV radiation in the most recent 30 years is $69.4 \sim 81.4 \mathrm{~kW} \cdot \mathrm{h} / \mathrm{m}^{2}$;

Zone III: the annual UV radiation in the most recent 30 years $\geq 81.4 \mathrm{~kW} \cdot \mathrm{h} / \mathrm{m}^{2}$.

According to the above zoning method, the climate zoning map of asphalt UV radiation in China is shown in Figure 3. 


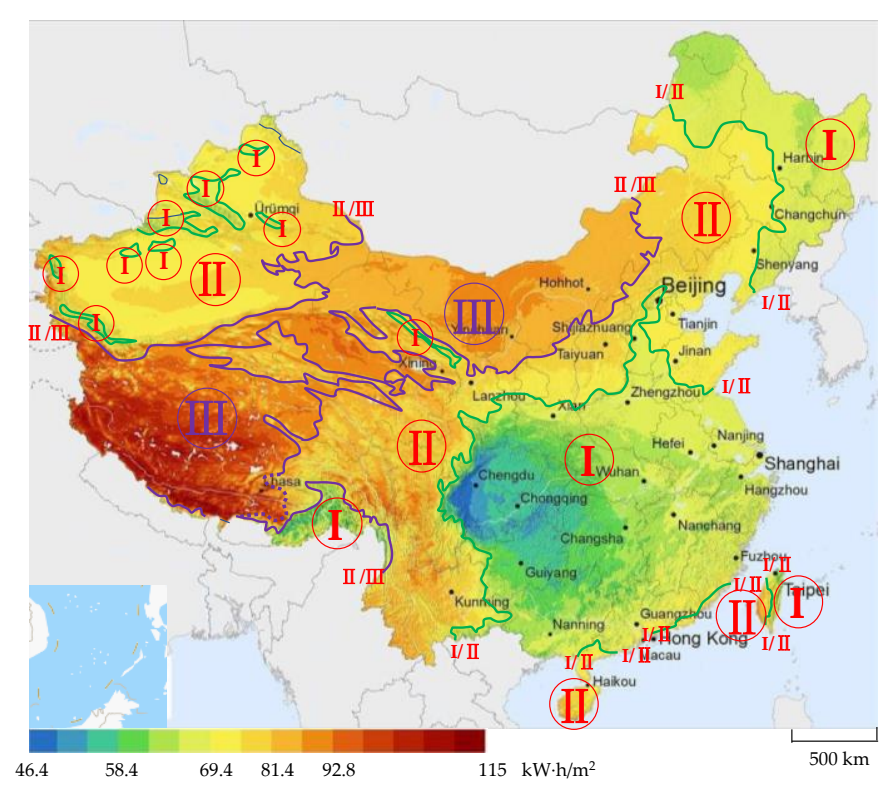

Figure 3. Climatic zoning of asphalt UV radiation in China (I/II is the boundary between zone I and zone II; II/III is the boundary between area II and area III).

\section{UV Aging Law of Asphalt}

\subsection{Test Scheme}

One of the key contents of this research was to reveal the aging rule of asphalt under UV radiation. In this paper, the viscosity, low-temperature, and rheological properties of various asphalt were tested under different UV radiation levels.

\subsubsection{Test Conditions}

In this paper, asphalt light aging test chamber YXW-1B was used. By changing the light source system and power of the UV lamp, five different UV irradiances, such as $31.5 \mathrm{~W} / \mathrm{m}^{2}, 63 \mathrm{~W} / \mathrm{m}^{2}, 94.5 \mathrm{~W} / \mathrm{m}^{2}, 126 \mathrm{~W} / \mathrm{m}^{2}$, and $157.5 \mathrm{~W} / \mathrm{m}^{2}$, were obtained. The main peak value of the spectrum was $365 \mathrm{~nm}$. Relevant studies have shown that the amount of UV aging of asphalt is related to the amount of UV radiation it receives, while the effect of irradiance is not so significant. Therefore, in order to shorten the test time, $157.5 \mathrm{~W} / \mathrm{m}^{2}$ was selected as the UV radiation intensity in this paper [11,13]. Relevant studies show that the temperature has little effect on the UV aging of asphalt within $80^{\circ} \mathrm{C}[13,19,25]$. In order to facilitate the test operation, the test temperature was selected as $60^{\circ} \mathrm{C}$. The test time was $0 \mathrm{~h}, 24 \mathrm{~h}, 48 \mathrm{~h}, 72 \mathrm{~h}, 96 \mathrm{~h}, 120 \mathrm{~h}, 144 \mathrm{~h}, 168 \mathrm{~h}$, and $192 \mathrm{~h}$. During the test, the asphalt film was controlled in the range of $200 \sim 500 \mu \mathrm{m}$ by controlling the amount of asphalt in a smooth and flat container.

\subsubsection{Raw Materials}

The grades of base bitumen widely used in China are $50^{\#}, 70^{\#}, 90^{\#}$, and $110^{\#}$, while $95 \%$ of the modified asphalt market is occupied by SBS modified asphalt, and the common SBS modified asphalt grades are SBS I-C and SBS I-D. Based on this, this paper selected $50^{\#}, 70^{\#}, 90^{\#}$, and $110^{\#}$ base asphalt (all A-grade asphalt), as well as SBS I-C and SBS I-D modified asphalt as test raw materials, and the technical indexes are shown in Table 1. 
Table 1. Technical parameters of asphalt used in this paper.

\begin{tabular}{|c|c|c|c|c|c|c|c|}
\hline & \multirow{2}{*}{ Technical Parameters } & \multicolumn{6}{|c|}{ Asphalt } \\
\hline & & $50^{\#}$ & $70^{\#}$ & $90^{\#}$ & $110^{\#}$ & SBS I-C & SBS I-D \\
\hline & Penetration at $25^{\circ} \mathrm{C}, 0.1 \mathrm{~mm}$ & 53.8 & 68.5 & 91.7 & 109.2 & 72.7 & 55.1 \\
\hline & Softening point, ${ }^{\circ} \mathrm{C}$ & 50.3 & 47.4 & 46.3 & 43.8 & 66.3 & 71.5 \\
\hline & Ductility at $10^{\circ} \mathrm{C}, \mathrm{cm}$ & 18.7 & 27.5 & 34.6 & 46.9 & - & - \\
\hline & Ductility at $5{ }^{\circ} \mathrm{C}, \mathrm{cm}$ & $\longrightarrow$ & $\longrightarrow$ & $\longrightarrow$ & $\longrightarrow$ & 35.3 & 27.8 \\
\hline \multirow{4}{*}{ RTFOT $^{1}$} & Mass Change, $\%$ & 0.5 & 0.45 & 0.67 & 0.71 & 0.87 & 0.73 \\
\hline & Residual penetration ratio at $25^{\circ} \mathrm{C}, \%$ & 71.1 & 68.9 & 66.5 & 62.3 & 75.8 & 71.3 \\
\hline & Residual ductility at $10^{\circ} \mathrm{C}, \mathrm{cm}$ & 7.6 & 9.1 & 10.2 & 13.4 & - & - \\
\hline & Residual ductility at $5^{\circ} \mathrm{C}, \mathrm{cm}$ & - & $\longrightarrow$ & $\longrightarrow$ & - & 25.3 & 19.7 \\
\hline
\end{tabular}

${ }^{1}$ RTFOT: Rolling Thin Film Oven Test.

\subsubsection{Test Design}

Under the test conditions of Section 3.1.1. The indexes such as penetration, softening point, and ductility of different asphalts under different UV aging time were tested, and the rheological indexes of asphalts were tested by using Dynamic Shear Rheometer.

\subsection{Analysis of Test Results}

\subsubsection{Penetration, Softening Point and Ductility}

Penetration is an important index to reflect the viscosity of asphalt. It is generally considered that with the deepening of aging degree, the penetration of both base asphalt and modified asphalt decreases in varying degrees, and the reduction of penetration is usually considered as an effective index to reflect the aging degree of asphalt. Figure 4 shows the asphalt penetration $\left(25^{\circ} \mathrm{C}\right)$ at the UV irradiation intensity of $157.5 \mathrm{~W} / \mathrm{m}^{2}$ under different UV irradiation times. Figure 5 shows the penetration loss rate of asphalt under different UV irradiation times.

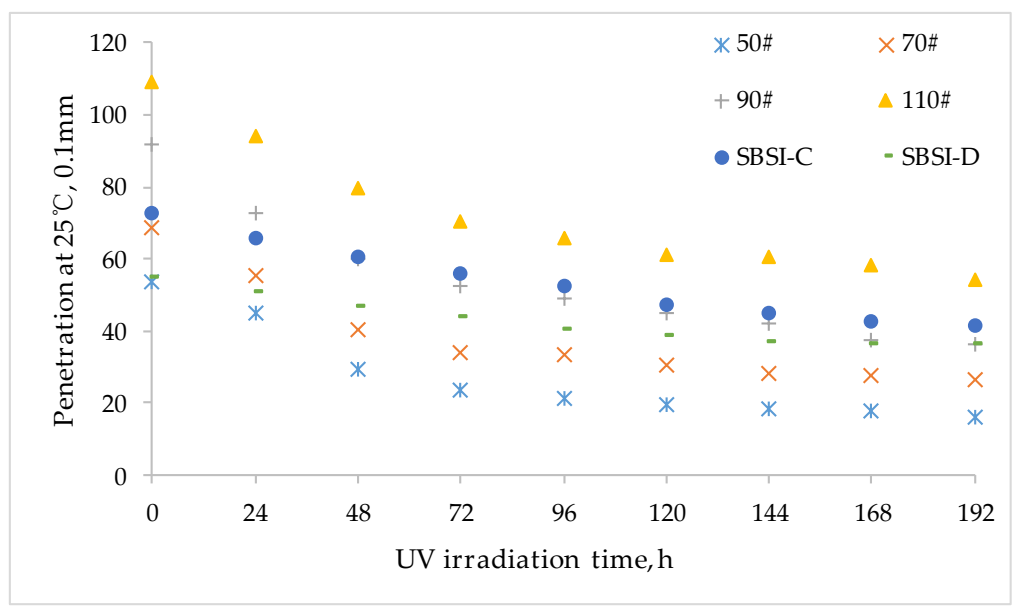

Figure 4. The penetration of asphalt with different UV irradiation time. 


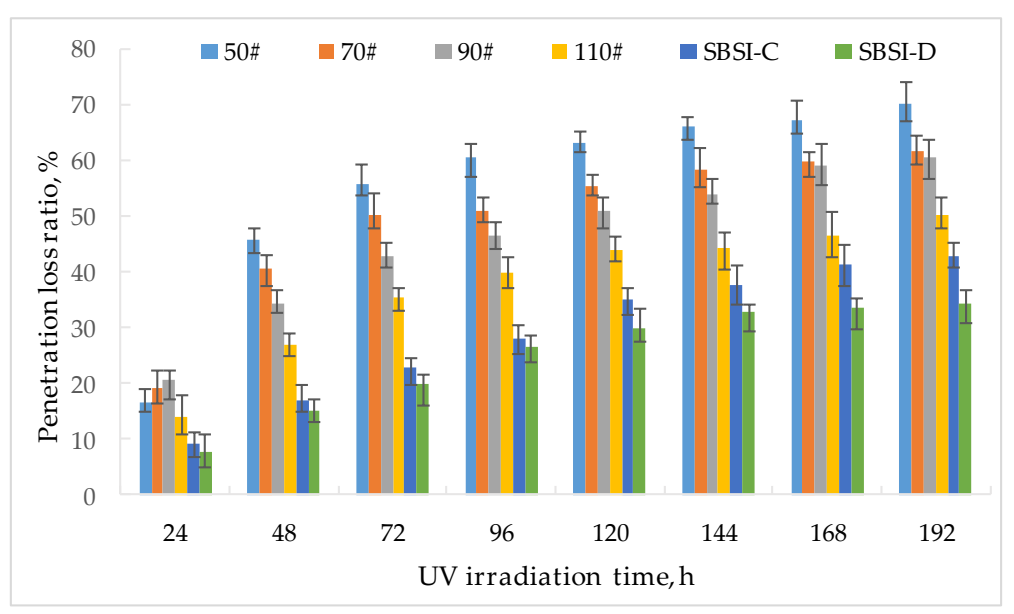

Figure 5. The penetration loss rate of asphalt with different UV irradiation time.

With the extension of UV irradiation time, the penetration of asphalt obviously decreased. From the point of decline, the lower the asphalt grade, the greater the decrease in penetration, but the absolute value of decrease was not very high. The decrease in penetration of SBS modified asphalt was obviously smaller than that of base asphalt, which shows that the anti-UV performance of SBS modified asphalt was better than that of base asphalt. In addition, the decrease in penetration of SBS I-D was lower than that of SBS I-C.

Generally, $87.21 \%$ of the temperature interval between the dropping point and the hardening point was taken as the softening point. Soft point is generally considered as an indicator of the thermal stability of asphalt materials, and also a measure of the conditional viscosity of asphalt. Relevant data show that UV radiation can increase the softening point of asphalt [7-9]. In this paper, the ring and ball method was used to determine the softening point. Figure 6 shows the asphalt softening point at the UV irradiation intensity of $157.5 \mathrm{~W} / \mathrm{m}^{2}$ under different UV irradiation times. Figure 7 shows the softening point loss rate of asphalt under different UV irradiation times.

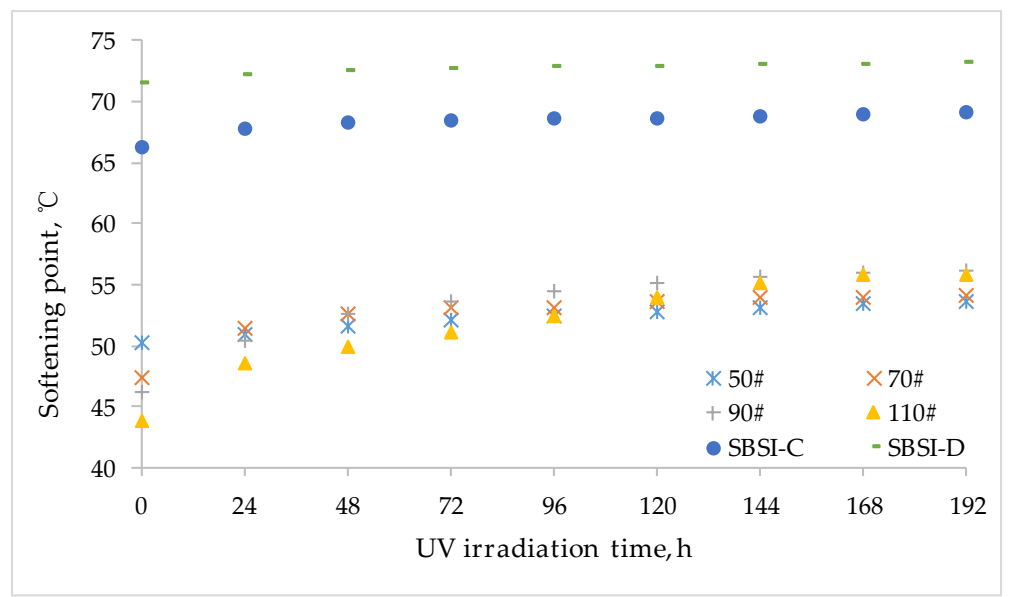

Figure 6. The softening point of asphalt with different UV irradiation time. 


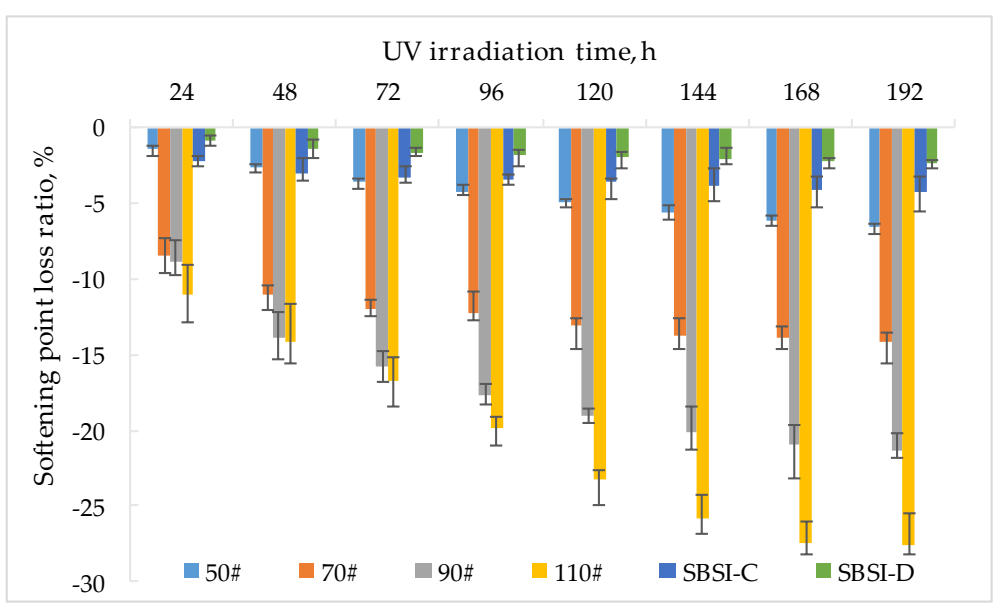

Figure 7. The softening point loss rate of asphalt with different UV irradiation time.

With the extension of UV irradiation time, the softening point of asphalt increased gradually. With the gradual increase in asphalt grade, the increase in softening point was larger, but the absolute value of increase was relatively small. The absolute decrease in the softening point of SBS modified asphalt was obviously smaller than that of base asphalt, which indicated that the anti-UV performance of SBS modified asphalt was better than that of base asphalt, and the increase in softening point of SBS I-D was lower than that of SBS I-C. In addition to high-grade base asphalt, the differentiation of softening point in the process of UV radiation was not very large, and the testing error in the process of softening point experiment made it more difficult to blur the differentiation, so the softening point index was not suitable as an index to evaluate the UV aging performance of asphalt.

Asphalt ductility is the total ability of the plastic deformation that the asphalt can bear when it is stretched by external forces, and it is a measure index of the cohesion of asphalt. The ductility of asphalt is closely related to the rheological properties of asphalt. In engineering, ductility is generally used as an important index of the low-temperature performance of asphalt, and its value is closely related to the low-temperature crack resistance of asphalt pavement. Figure 8 shows the asphalt ductility at the UV irradiation intensity of $157.5 \mathrm{~W} / \mathrm{m}^{2}$ under different UV irradiation times. Figure 9 shows the ductility loss rate of asphalt under different UV irradiation times.

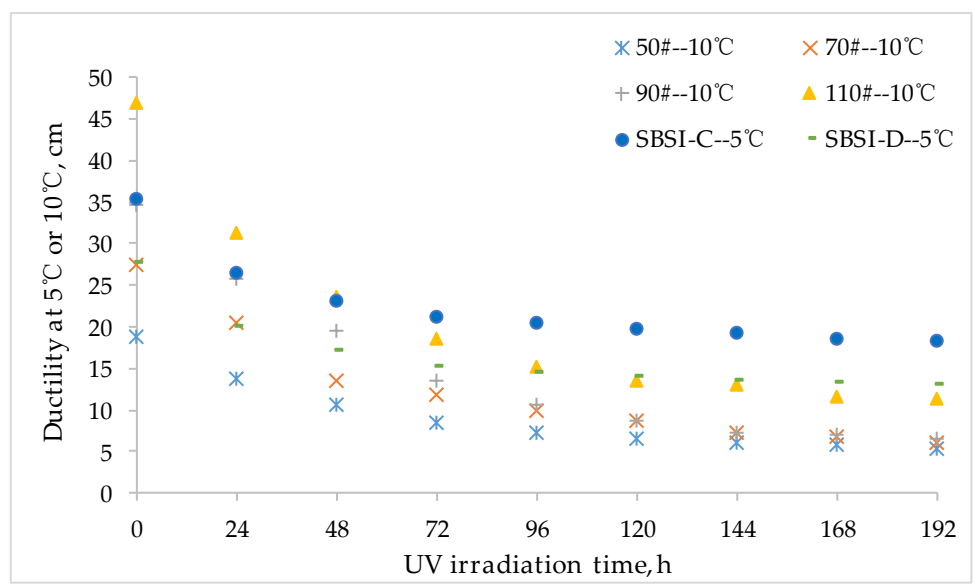

Figure 8. The ductility of asphalt with different UV irradiation time (the test temperature of base asphalt is $10^{\circ} \mathrm{C}$ while that of SBS modified asphalt is $5^{\circ} \mathrm{C}$ ). 


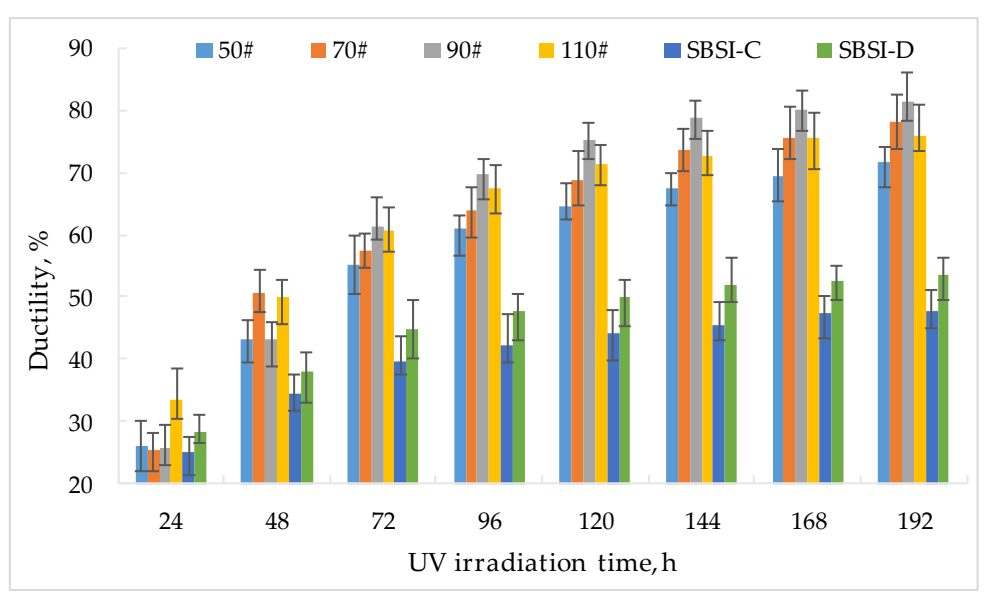

Figure 9. The ductility loss rate of asphalt with different UV irradiation time (the test temperature of base asphalt is $10^{\circ} \mathrm{C}$ while that of SBS modified asphalt is $5^{\circ} \mathrm{C}$ ).

With the extension in UV irradiation time, the ductility of asphalt decreased gradually. The grade of base asphalt had little effect on the ductility loss rate. For SBS modified asphalt, when the UV irradiation time was within $24 \mathrm{~h}$, the loss rate of the ductility of SBS modified asphalt was basically equal to that of base asphalt. However, when the UV irradiation time was over $24 \mathrm{~h}$, the absolute decrease in the ductility of SBS modified asphalt was significantly smaller than that of matrix asphalt, although the test temperature of this data was only $5{ }^{\circ} \mathrm{C}$. This suggests that that the anti-UV performance of SBS modified asphalt was better than that of base asphalt. In addition, the decrease of ductility of SBS I-D was lower than that of SBS I-C.

In the process of UV radiation, the light components in asphalt, such as aromatics, volatilize, resulting in the loss of asphalt quality, so the mass loss rate is generally used as an index to evaluate the aging degree of asphalt. Figure 10 shows the asphalt mass loss rate at the UV irradiation intensity of $157.5 \mathrm{~W} / \mathrm{m}^{2}$ under different UV irradiation times.

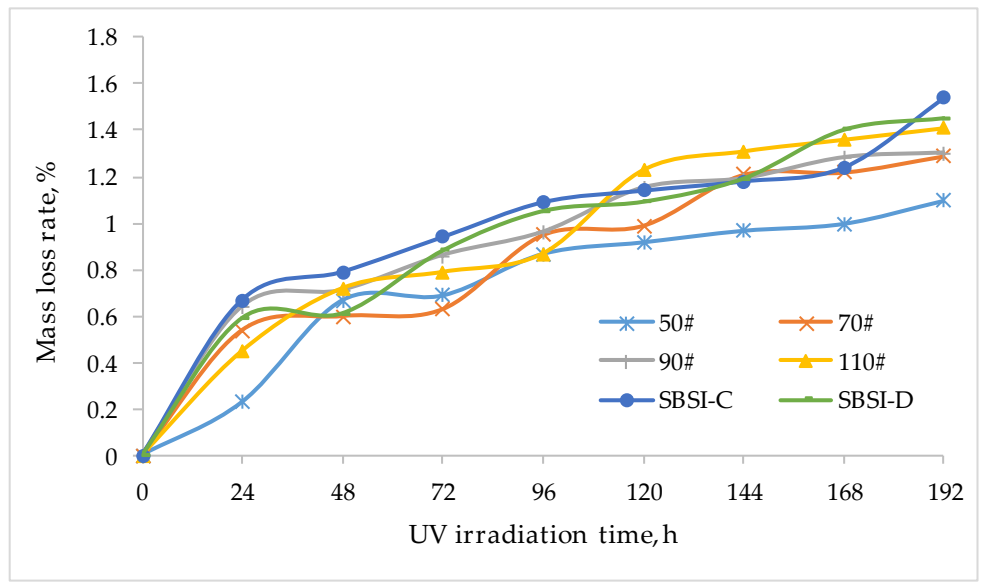

Figure 10. The mass loss rate of asphalt with different UV irradiation time.

Figure 10 shows that, with the extension of UV aging time, the mass loss of asphalt basically presented a gradually increasing trend, which reflected the aging degree of asphalt from one side. However, due to the large error in the data acquisition process of this experiment, generally, the data were more inclined to be used for qualitative research.

\subsubsection{Rheological Properties of Asphalt}

The dynamic shear rheometer (DSR) developed by the Strategic Highway Research Program comprehensively considers the influence of loading condition and temperature 
on asphalt performance, and determines the complex modulus $\left(\mathrm{G}^{*}\right)$, Phase Angle $(\delta)$, and Rutting Factor $\left(\mathrm{G}^{*} / \mathrm{Sin} \delta\right)$ that were used to evaluate the high-temperature performance of the asphalt. In this paper, the dynamic shear rheometer was used to test the rheological properties of asphalt under different UV irradiation times $(0 \mathrm{~h}, 48 \mathrm{~h}, 96 \mathrm{~h}, 144 \mathrm{~h}$, and $196 \mathrm{~h})$. The irradiation intensity was $157.5 \mathrm{~W} / \mathrm{m}^{2}$, and the test temperature range was $40 \sim 76{ }^{\circ} \mathrm{C}$. $G^{*}, \delta$, and $G^{*} / \sin \delta$ of asphalt were measured. Figure 11 shows the $G^{*}$ and $\delta$ of different asphalts under different UV irradiation times and temperatures. Figure 12 shows the $\mathrm{G}^{*} / \sin \delta$ of different asphalts under different UV irradiation times and temperatures.

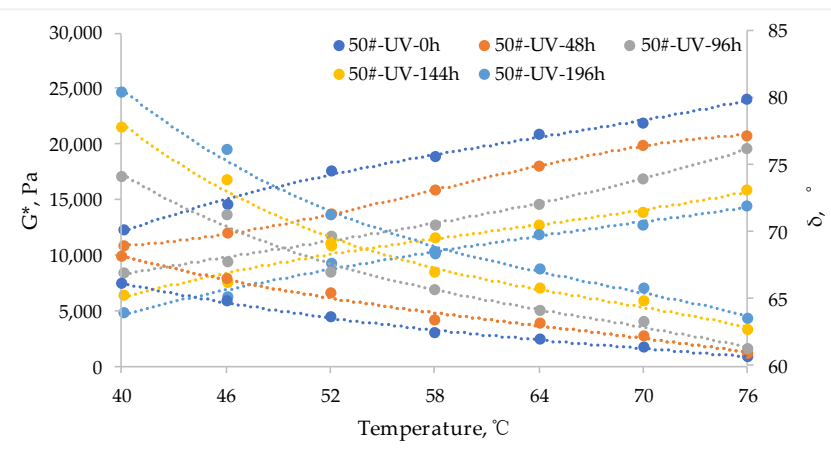

(a)

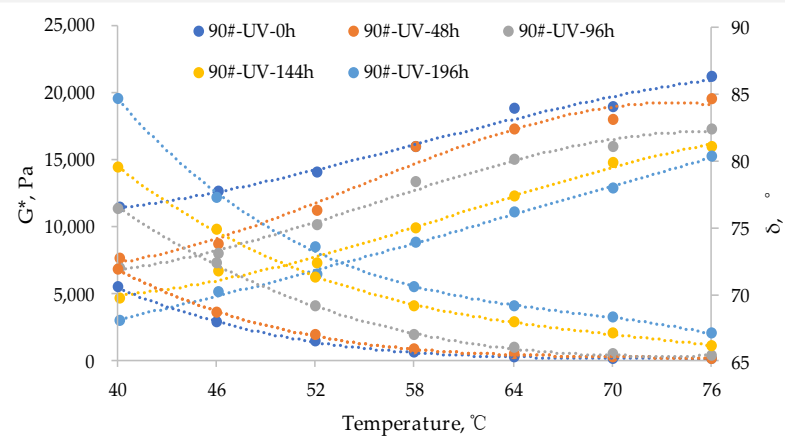

(c)

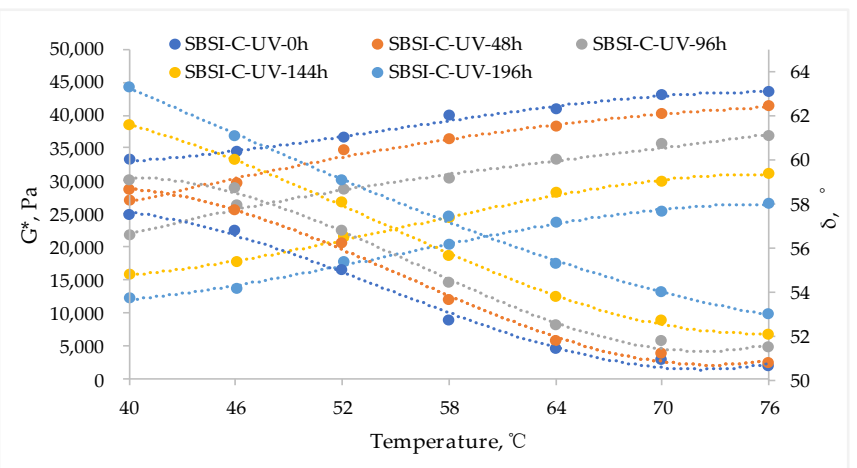

(e)

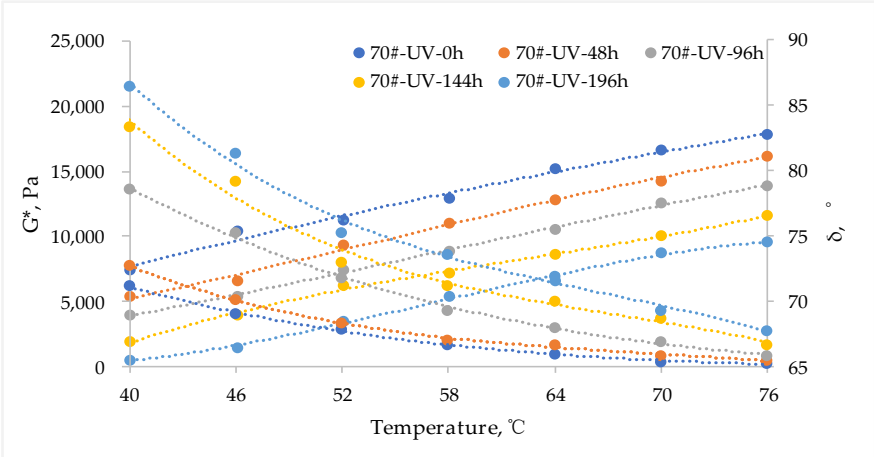

(b)

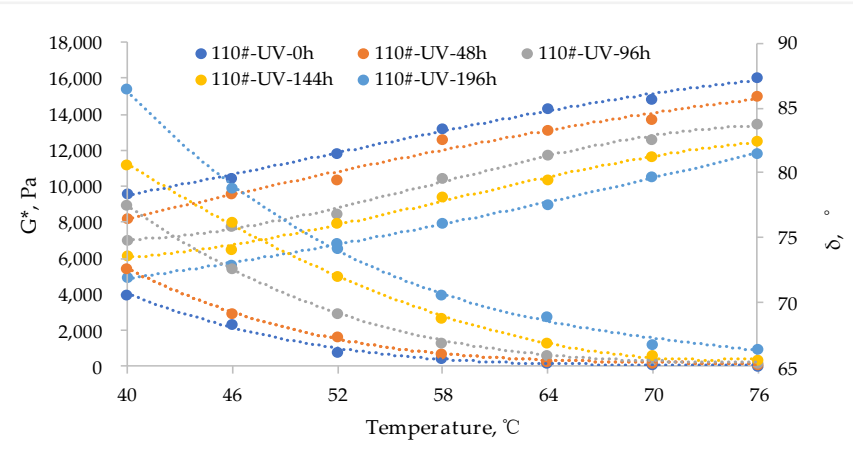

(d)

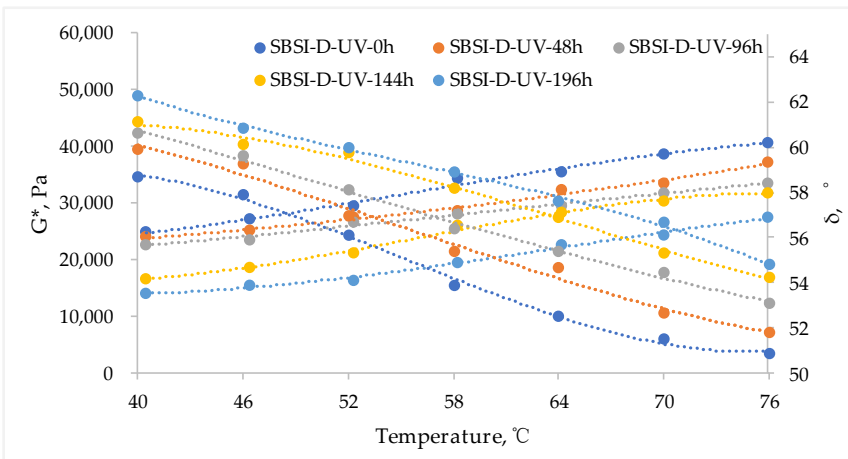

(f)

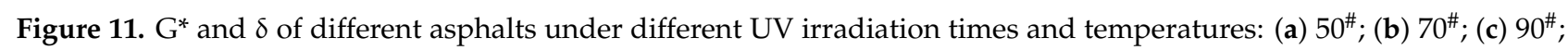
(d) $110^{\#}$; (e) SBS I-C; (f) SBS I-D. 


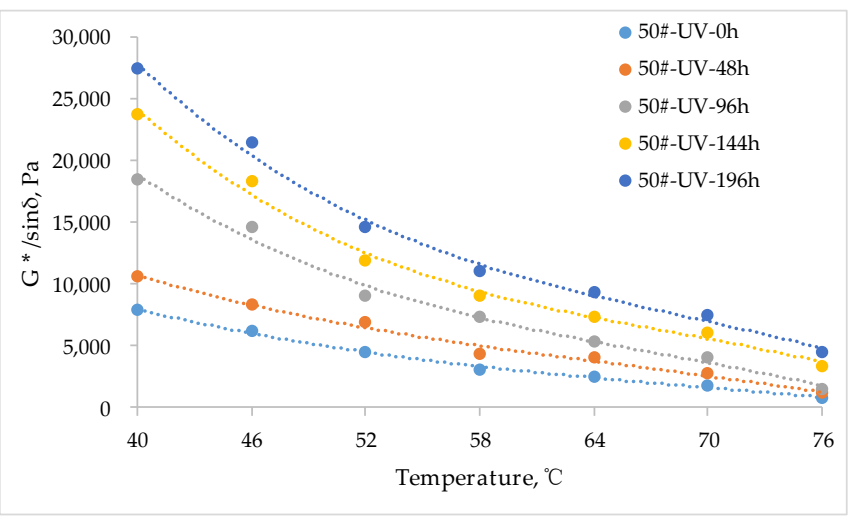

(a)

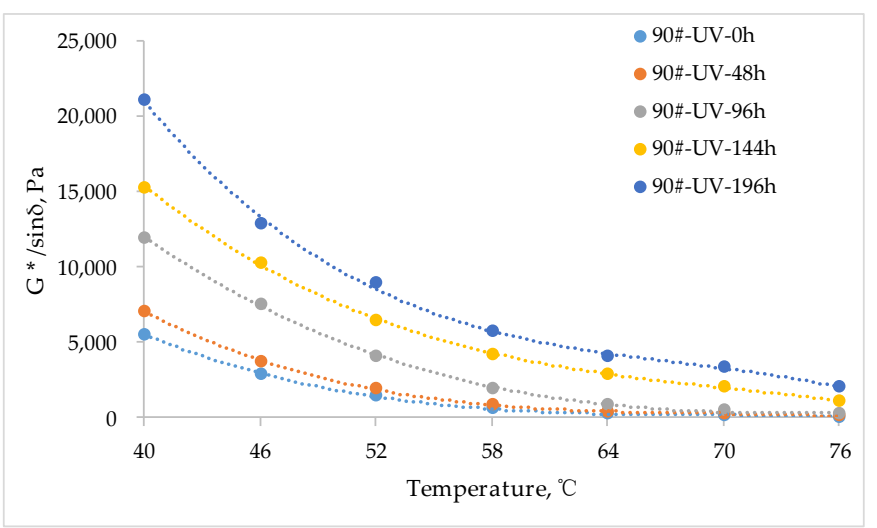

(c)

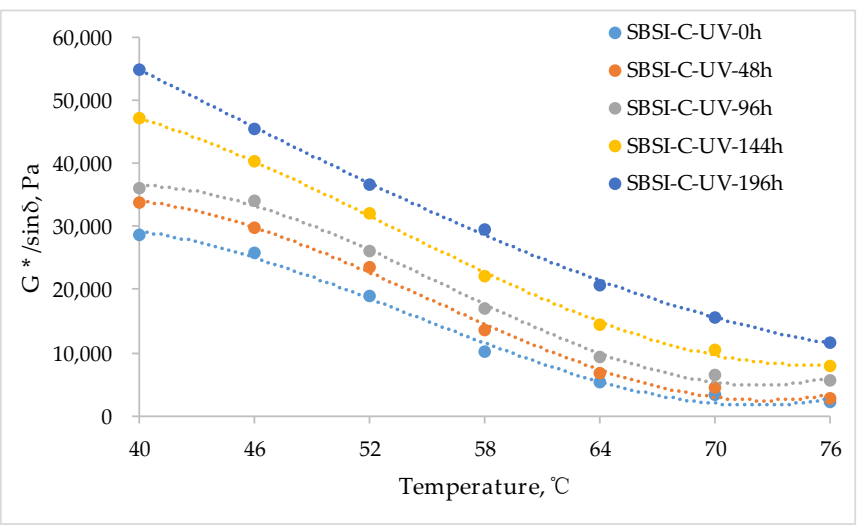

(e)

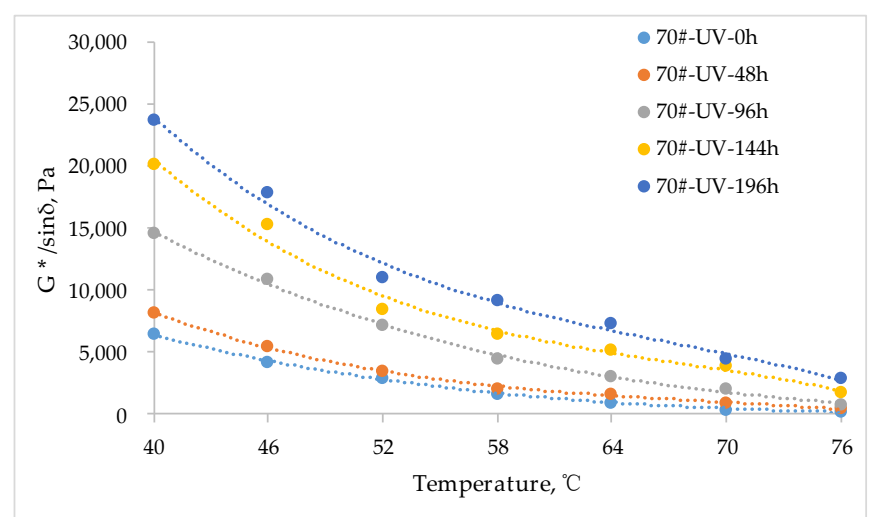

(b)

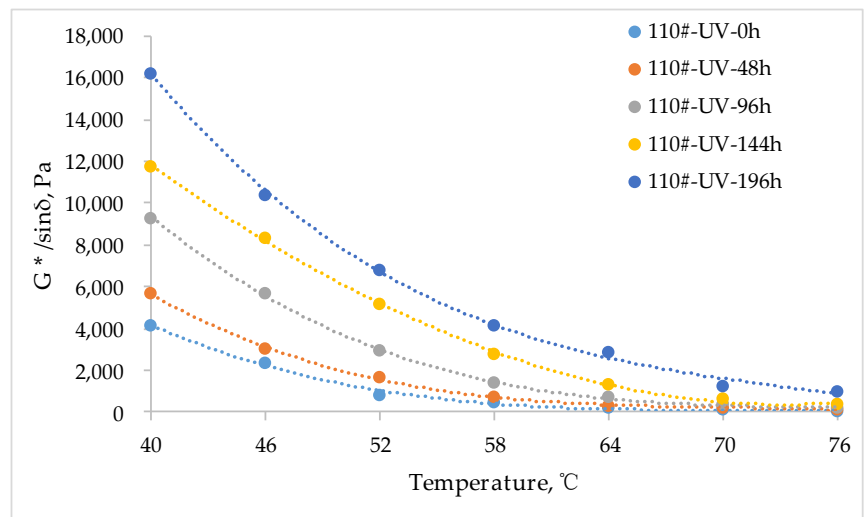

(d)

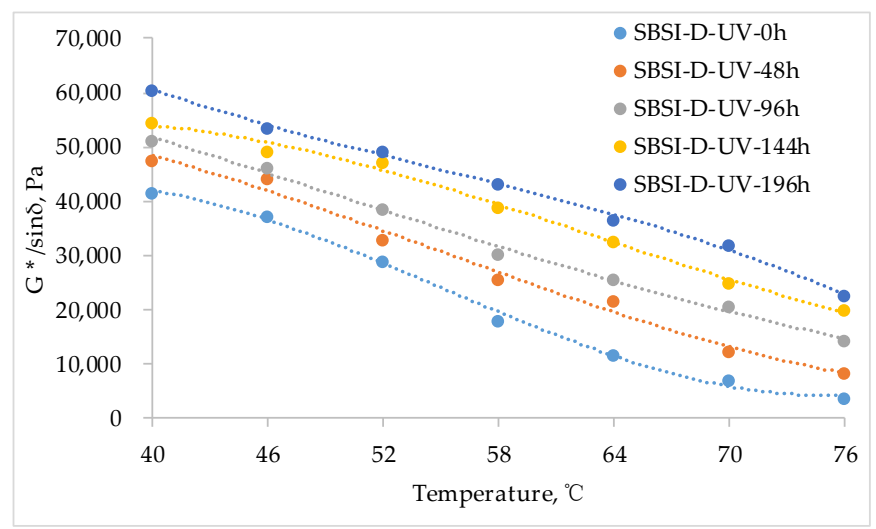

(f)

Figure 12. $\mathrm{G}^{*} / \sin \delta$ of different asphalts under different UV irradiation times and temperatures: (a) $50^{\#}$; (b) $70^{\#}$; (c) $90^{\# \text {; }}$ (d) $110^{\#}$; (e) SBS I-C; (f) SBS I-D.

Figure 11 shows that the $G^{*}$ increased and $\delta$ decreased with increasing UV aging time. The elastic component of the asphalt response became more dominant and the viscous component less dominant with UV aging. Figure 12 shows that the longer the UV irradiation time, the bigger the $\mathrm{G}^{*} / \sin \delta$ of asphalt at the same scanning temperature. Relevant studies show that $\mathrm{G}^{*} / \sin \delta$ can be used to evaluate the rutting resistance of asphalt, and the higher the value is, the better the rutting resistance of asphalt will be [13-15]. Of course, the change in anti-rutting performance was only one of many performance changes. The magnitude of the change also indirectly indicates the aging effect of UV on asphalt. In fact, in addition to the anti-rutting performance, the durability and anti-fatigue performance of asphalt are also 
very important, and relevant research reports show that ultraviolet radiation is not conducive to the durability and anti-fatigue performance of asphalt [13,15].

By comparing the change law of $\mathrm{G}^{*} / \sin \delta$ of different asphalt after UV irradiation, it is not difficult to find that the higher the asphalt grade, the smaller the $G^{*} / \sin \delta$ value at the same scanning temperature, and the worse the high-temperature performance. This law was applicable to any scanning temperature in the process of the experiment. In terms of $\mathrm{G}^{*} / \sin \delta$ values, SBS modified asphalt was much higher than base asphalt under the same UV irradiation time and scanning temperature, indicating that the high-temperature performance of SBS modified asphalt under the same UV irradiation condition was much higher than that of base asphalt.

By summarizing the rheological properties of asphalt in the process of UV radiation, it can be concluded that UV radiation changes the proportion of viscous components and elastic components in asphalt. The specific performance is that the proportion of viscous components decreases and the proportion of elastic components increases, which leads to the change in the asphalt's high-temperature resistance to permanent deformation. With the increase in UV radiation, the magnitude of the change is greater.

\section{UV Prevention Strategies Based on Aging Equivalence Relationships}

\subsection{Selection of Aging Equivalent Index}

The mechanism of UV aging and the thermal oxygen aging of asphalt are similar, caused by the volatilization of light oil in asphalt, the transformation of light oil to resins, and the transformation of resins to asphaltene [43-45]. However, the two aging methods are not exactly the same. Asphalt has different sensitivities to thermal aging and ultraviolet aging condition. The ultraviolet aged asphalts compositors in penetration, softening point, and ductility tests do not accord with thermally aged asphalts. Ultraviolet aging and thermal aging influence asphalt in different ways: rheological property changes greatly after ultraviolet aging [21]. Therefore, the selection of UV aging evaluation indexes should refer to the evaluation indexes of oxygen aging of hot asphalt. It is clear that the indexes that meet the requirements are penetration, softening point, ductility, mass loss rate, $G^{*}, \delta$, and $\mathrm{G}^{*} / \sin \delta$ after $\mathrm{UV}$ aging.

The purpose of this paper is to give the corresponding measures to prevent and control UV aging of asphalt based on the amount of UV radiation in different areas. Therefore, it is necessary to establish the equivalent relationship of UV aging of asphalt between different UV radiation zones, and the aging equivalence indexes need to meet the following requirements:

- The index is sensitive to UV radiation and has a certain degree of discrimination;

- The index has a strong regularity with the UV radiation, and the UV aging equation can be established to track the index;

- The index is easy to obtain, the error is small, and it can be popularized.

According to the research results in Section 3, among the asphalt indexes after UV aging such as penetration, softening point, ductility, mass loss rate, $G^{*}, \delta$, and $G^{*} / \sin -\delta$, the distinction of softening point and mass loss of asphalt are not very high, and the test error has a great influence on the results, which does not meet the requirements of aging equivalence indexes. Although $\mathrm{G}^{*}, \delta$, and $\mathrm{G}^{*} / \sin \delta$ are sensitive to $\mathrm{UV}$ radiation and have stable data, such indexes, however, have not been included in "Technical specifications for construction of highway asphalt pavement" (JTG F40-2004) [46]. In addition, the dynamic shear rheometer to obtain such indexes is only equipped in a few universities and scientific research institutes, while design and construction companies are rarely equipped with this, so such indexes do not have the conditions of being able to be popularized in China.

To sum up, this paper selects penetration loss rate and ductility loss rate of asphalt after UV aging as aging equivalent indexes. 


\subsection{UV Aging Equation of Asphalt}

Establishing the UV aging equation and quantifying the asphalt aging indexes under UV irradiation to realize the UV prevention measures in different zones is an important step. Through analysis, the UV aging process of asphalt can be characterized by the asphalt aging dynamic equation, as shown in Equation (1). According to the test results of asphalt penetration and ductility at different UV aging times in this paper, the dynamic equation of asphalt UV aging can be obtained, and the values of asphalt penetration and ductility at other aging times can also be estimated according to this equation. The dynamic equation of asphalt UV aging is shown in Table 2.

$$
\mathrm{P}(t)=\frac{a y_{0}}{1+(a-1) e^{-b t}}
$$

where: $\mathrm{P}(t)$ is the index value of asphalt under $\mathrm{UV}$ aging at time $t$; $\mathrm{a}$ and $b$ are the calculation parameters.

Table 2. UV aging equations of various asphalt involved in this paper.

\begin{tabular}{|c|c|c|c|}
\hline Asphalt & Indexes & Dynamic UV Aging Equation & $\mathbf{R}^{2}$ \\
\hline \multirow{2}{*}{$50^{\#}$} & Penetration at $25^{\circ} \mathrm{C}, 0.1 \mathrm{~mm}$ & $\mathrm{P}(t)=-0.0830 /\left(1-1.0016 \times \mathrm{e}^{0.0080 t}\right)$ & 0.93 \\
\hline & Ductility at $10^{\circ} \mathrm{C}, \mathrm{cm}$ & $\mathrm{P}(t)=-0.0037 /\left(1-1.0002 \times \mathrm{e}^{0.0090 t}\right)$ & 0.95 \\
\hline \multirow{2}{*}{$70^{\#}$} & Penetration at $25^{\circ} \mathrm{C}, 0.1 \mathrm{~mm}$ & $\mathrm{P}(t)=-0.0070\left(1-1.0001 \times \mathrm{e}^{0.0070 t}\right)$ & 0.96 \\
\hline & Ductility at $10^{\circ} \mathrm{C}, \mathrm{cm}$ & $\mathrm{P}(t)=-0.0385 /\left(1-1.00144 \times \mathrm{e}^{0.0103 t}\right)$ & 0.98 \\
\hline \multirow{2}{*}{$90^{\#}$} & Penetration at $25^{\circ} \mathrm{C}, 0.1 \mathrm{~mm}$ & $\mathrm{P}(t)=3.7597 /\left(1-0.9590 \times \mathrm{e}^{0.0060 t)}\right.$ & 0.97 \\
\hline & Ductility at $10^{\circ} \mathrm{C}, \mathrm{cm}$ & $\mathrm{P}(t)=-0.0440 /\left(1-1.0013 \times \mathrm{e}^{0.0114 t}\right)$ & 0.96 \\
\hline \multirow{2}{*}{$110^{\#}$} & Penetration at $25^{\circ} \mathrm{C}, 0.1 \mathrm{~mm}$ & $\mathrm{P}(t)=-0.3276 /\left(1-1.0300 \times \mathrm{e}^{0.0040 t}\right)$ & 0.98 \\
\hline & Ductility at $10^{\circ} \mathrm{C}, \mathrm{cm}$ & $\mathrm{P}(t)=-0.0327 /\left(1-1.0007 \times \mathrm{e}^{1.01087 t}\right)$ & 0.99 \\
\hline \multirow{2}{*}{ SBS I-C } & Penetration at $25^{\circ} \mathrm{C}, 0.1 \mathrm{~mm}$ & $\mathrm{P}(t)=0.0247 /\left(1-0.99966 \times \mathrm{e}^{0.0033 t}\right)$ & 0.97 \\
\hline & Ductility at $5^{\circ} \mathrm{C}, \mathrm{cm}$ & $\mathrm{P}(t)=0.0055 /\left(1-0.99843 \times \mathrm{e}^{0.0475 t}\right)$ & 0.94 \\
\hline \multirow{2}{*}{ SBS I-D } & Penetration at $25^{\circ} \mathrm{C}, 0.1 \mathrm{~mm}$ & $\mathrm{P}(t)=4.2360 /\left(1-0.92311 \times \mathrm{e}^{0.0027 t}\right)$ & 0.96 \\
\hline & Ductility at $5^{\circ} \mathrm{C}, \mathrm{cm}$ & $\mathrm{P}(t)=-30.8858 /\left(1-2.1110 \times \mathrm{e}^{0.0056 t}\right)$ & 0.95 \\
\hline
\end{tabular}

$\mathrm{P}(t)$ represents penetration or ductility under UV aging at time $t$.

In Equation (1), ' $a$ ' is related to the ratio of asphalt Index $\mathrm{P}(t)$ at time $t$ and initial time, for a given ' $a$ ', ' $b$ ' is related to the increasing rate (or decreasing rate) of asphalt Index $\mathrm{P}(t)$.

\subsection{Equivalent Relation of $U V$ Aging of Asphalt}

At present, the anti-UV aging asphalt and related projects in China have mostly stayed at the level of the trial road, and there are no UV-resistant aging pavement projects on a provincial scale. This is mainly limited by the benefit ratio, that is to say, in a large range of China, especially in the UV radiation climate zone I, the promotion of anti-UV aging technology is of low benefit and difficult. Therefore, this paper puts forward the concept of equivalent $\mathrm{UV}$ aging of asphalt, i.e., taking the dividing line of $\mathrm{UV}$ radiation climate zone I and zone II $\left(69.4 \mathrm{~kW} \cdot \mathrm{h} / \mathrm{m}^{2}\right)$ as the benchmark, with the help of the relationship between the maximum UV radiation and the benchmark radiation in zone II and zone III and the UV aging equation of asphalt, the equivalent UV aging of asphalt (i.e., the same UV radiation amount) can be converted with the equivalent time of zone II and zone III (laboratory time and outdoor time). In the same way, the amount of UV radiation and asphalt aging can also be calculated under the same UV radiation time. In this paper, six months of outdoor irradiation in zone I is selected as the baseline UV irradiation time and amount, and the relationship between the equivalent time and the equivalent radiation amount of different UV climatic zones is shown in Tables 3 and 4. 
Table 3. Equivalent time of outdoor under the same UV radiation and test time.

\begin{tabular}{cccc}
\hline UV Climatic Zones & $\begin{array}{c}\text { UV Radiation } \\
\text { in Laboratory, } \\
\mathbf{k W} \cdot \mathbf{h} / \mathbf{m}^{\mathbf{2}}\end{array}$ & $\begin{array}{c}\text { Test Time } \\
\text { in Laboratory, } \mathbf{h}\end{array}$ & $\begin{array}{c}\text { Equivalent Time } \\
\text { of Outdoor, Months }\end{array}$ \\
\hline I & 34.7 & 110 & 6 \\
II & 34.7 & 110 & 5.1 \\
III & 34.7 & 110 & 3.6 \\
\hline
\end{tabular}

Table 4. Equivalent test time in the laboratory under the different UV radiation (Take 6 months as an example).

\begin{tabular}{cccc}
\hline UV Climatic Zones & $\begin{array}{c}\text { Time of Outdoor, } \\
\text { months }\end{array}$ & $\begin{array}{c}\text { UV Radiation } \\
\text { in Laboratory, } \\
\mathbf{k W} \cdot \mathbf{h} / \mathbf{m}^{\mathbf{2}}\end{array}$ & $\begin{array}{c}\text { Equivalent Test Time } \\
\text { in Laboratory, } \mathbf{h}\end{array}$ \\
\hline I & 6 & 34.7 & 110 \\
II & 6 & 40.7 & 129 \\
III & 6 & 57.5 & 183 \\
\hline
\end{tabular}

According to the test data obtained in this paper, the penetration loss rate and ductility loss rate of asphalt in different UV climate zones are obtained by taking the actual outdoor UV radiation for 6 months as the test time (see Table 4 for indoor test time), as shown in Table 5.

Table 5. The penetration loss rate and ductility loss rate of asphalt in different UV climate zones (taking the actual outdoor UV radiation for 6 months as the test time).

\begin{tabular}{ccccccc}
\hline \multirow{2}{*}{ Asphalt } & \multicolumn{3}{c}{ Penetration Loss Rate, \% } & \multicolumn{3}{c}{ Ductility Loss Rate, \% } \\
\cline { 2 - 6 } & I & II & III & I & II & III \\
\hline $50^{\#}$ & 62.1 & 64.5 & 69.5 & 63.1 & 65.8 & 71.1 \\
$70^{\#}$ & 53.7 & 57.2 & 61.0 & 68.0 & 70.9 & 76.7 \\
$90^{\#}$ & 49.0 & 52.6 & 57.3 & 71.7 & 76.0 & 80.3 \\
$110^{\#}$ & 41.8 & 44.0 & 49.5 & 69.3 & 72.3 & 75.7 \\
SBS I-C & 31.9 & 36.3 & 39.6 & 43.1 & 46.5 & 49.6 \\
SBS I-D & 28.3 & 30.3 & 36.1 & 48.9 & 51.4 & 56.8 \\
\hline
\end{tabular}

Tables 5 and 6 show that under the same outdoor UV irradiation time, compared with zone I, the increment of penetration loss rate of asphalt in zone II is less than $5 \%$, with an average of $3 \%$, and the increment of ductility loss rate is less than $5 \%$, with an average of $3.2 \%$. In addition, under the same outdoor UV irradiation time, compared with zone I, the increment of penetration loss rate of asphalt in Zone III is less than $10 \%$, with an average of $7.7 \%$, and the increment of ductility loss rate is less than $10 \%$, with an average of $7.7 \%$. Based on the above laws, under the same outdoor UV irradiation time, in order to achieve the same technical performance as zone I, the asphalt anti-UV ability of zone II should be increased by more than $5 \%$, and that of zone III should be increased by more than $10 \%$. 
Table 6. The difference from zone I of penetration loss rate (the penetration loss rate and ductility loss rate of asphalt in UV climate zone II and III).

\begin{tabular}{ccccc}
\hline \multirow{2}{*}{ Asphalt } & $\begin{array}{c}\text { Penetration Loss Rate, \%, } \\
\text { (The Difference from I, \%) }\end{array}$ & \multicolumn{2}{c}{$\begin{array}{c}\text { Ductility Loss Rate, \%, } \\
\text { (The Difference from I, \%) }\end{array}$} \\
\cline { 2 - 5 } & II & III & II & III \\
\hline $50^{\#}$ & 2.4 & 7.4 & 2.7 & 8.0 \\
$70^{\#}$ & 3.5 & 7.3 & 2.9 & 8.7 \\
$90^{\#}$ & 3.6 & 7.3 & 4.3 & 8.7 \\
$110^{\#}$ & 2.1 & 7.7 & 3.0 & 6.4 \\
SBS I-C & 4.4 & 7.7 & 3.4 & 6.5 \\
SBS I-D & 2.0 & 7.8 & 2.5 & 7.9 \\
\hline
\end{tabular}

\section{Examples of UV Aging Prevention of Asphalt}

\subsection{Selection of Trial Section}

In order to verify the feasibility of the above theory in the actual project, the study tries to make a comparison through the use of a trial road. The trial road needs to meet the relatively harsh conditions as follows:

- The trial road crosses at least two climatic zones of UV radiation, and the annual radiation amount difference is large.

- The pavement structure, construction materials, construction machinery, construction technology, and completion time of all sections of the trial road are the same.

- The traffic volume after opening to traffic is basically the same.

In order to meet the above conditions, basically, the trial road needs to be exactly the same in all areas of the highway, the same construction company will be used, and the highway needs to cross two UV radiation climate zones.

The project searched all over China, and finally the entity project, Yonggu Expressway in Gansu Province, China, was selected. The prominent feature of the expressway is that it is located in an area of rapid change in solar resources, passing through UV radiation zone I and UV radiation zone II.

Three sections of the trial road were selected in this project. Trial section 1 was located in zone I of UV radiation, trial section 2 was located in zone II of UV radiation, and trial section 3 was the contrast section, next to trial section 2, which was also zone II of UV radiation. The three trial sections were all completed by the same construction company with the same pavement structure, road construction machinery, road construction materials (excluding anti-UV aging agent), and road construction technology in a close period of time, and the opening time was the same. The traffic volume and traffic composition after opening to traffic was almost the same. Figure 13 shows the comparison of UV radiation in the three trial sections.

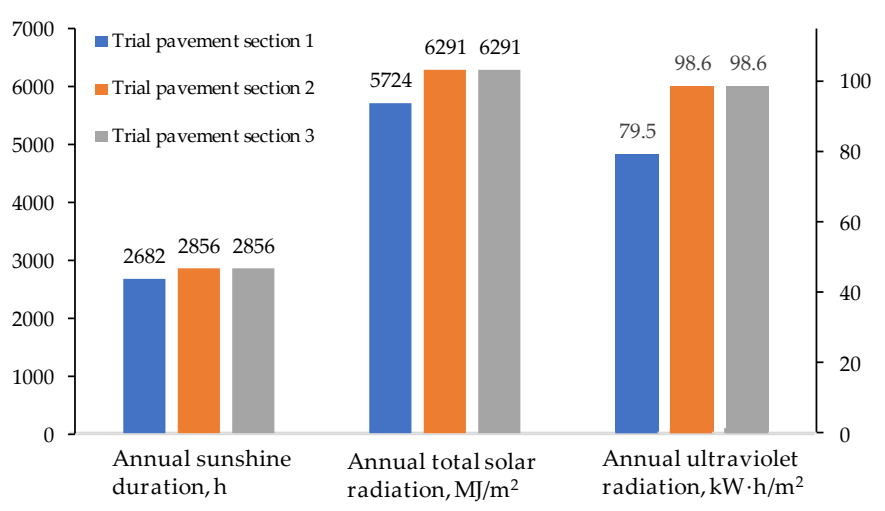

Figure 13. The comparison of UV radiation in three trial sections. 


\subsection{Anti-UV Aging Scheme}

The anti-UV aging agent used in this paper was composed of antioxidant 1010 (A 1010) and light stabilizer 770 (L 770). The ratio of the two substances was A 1010: L $770=5: 2$, and the content of the anti-UV aging agent was $0.7 \%$ of asphalt mass. SBS I-C modified asphalt was used for construction. SBS I-C modified asphalt without anti-UV aging agent was used for trial section 1 and trial section 2, while SBS I-C modified asphalt with $0.7 \%$ anti-UV aging agent was used for trial section 3. In the design process, according to the principle of equivalent aging, the anti-UV aging performance in zone II of SBS I-C modified asphalt with the anti-UV aging agent could reach the performance level of SBS I-C (without the anti-UV aging agent) in zone I. The technical indexes of asphalt used in the trial sections are shown in Table 7.

Table 7. The technical indexes of asphalt used in the trial sections.

\begin{tabular}{|c|c|c|c|}
\hline \multicolumn{2}{|c|}{ Indexes } & SBS I-C & SBS I-C with Anti-UV Aging Agent \\
\hline \multirow{3}{*}{\multicolumn{2}{|c|}{$\begin{array}{l}\text { Penetration, } 0.1 \mathrm{~mm} \\
\text { softening point, }{ }^{\circ} \mathrm{C} \\
\text { ductility at } 5{ }^{\circ} \mathrm{C}, \mathrm{cm}\end{array}$}} & 68.2 & 69.6 \\
\hline & & 60.9 & 59.9 \\
\hline & & 40.1 & 40.7 \\
\hline \multirow{2}{*}{$\begin{array}{l}\text { Penetration loss rate } \\
\text { after UV aging, \% }\end{array}$} & $157.5 \mathrm{~W} / \mathrm{m}^{2}, 110 \mathrm{~h}$ & 30.8 & - \\
\hline & $157.5 \mathrm{~W} / \mathrm{m}^{2}, 129 \mathrm{~h}$ & - & 30.5 \\
\hline \multirow{2}{*}{$\begin{array}{c}\text { Ductility loss rate at } 5{ }^{\circ} \mathrm{C} \\
\text { after UV aging, \% }\end{array}$} & $157.5 \mathrm{~W} / \mathrm{m}^{2}, 110 \mathrm{~h}$ & 42.9 & - \\
\hline & $157.5 \mathrm{~W} / \mathrm{m}^{2}, 129 \mathrm{~h}$ & - & 43.1 \\
\hline
\end{tabular}

\subsection{Results Observation}

In the first two years after the trial section of the project was completed and opened to traffic, there were no obvious diseases. In the third year of opening to traffic, there were relatively more transverse cracks and a few pits in trial road 2. The maintenance department repaired the cracks randomly. In addition, the loose disease appeared in all three trial sections, but trial section 2 was the most serious. The disease situation for each trial section is shown in Table 8, and the representative disease photos are shown in Figure 14 .

Table 8. The disease situation of each trial section.

\begin{tabular}{|c|c|c|c|c|c|}
\hline Trial Sections & UV Zones & Project Overview & Observation Time & Disease Situation & $\mathrm{PCI}^{1}$ \\
\hline Trial 1 & I & \multirow{3}{*}{$\begin{array}{l}\text { The anti-UV aging agent } \\
\text { is used in trial section } 2, \\
\text { and the other working } \\
\text { conditions are basically } \\
\text { the same }\end{array}$} & \multirow{3}{*}{$\begin{array}{l}\text { The beginning of the } \\
\text { third year }\end{array}$} & $\begin{array}{l}\text { Almost no disease, } \\
\text { light loose disease }\end{array}$ & 94 \\
\hline Trial 2 & II & & & $\begin{array}{c}\text { There are transverse } \\
\text { cracks and a few pits, } \\
\text { loose disease }\end{array}$ & 91 \\
\hline Trial 3 & III & & & $\begin{array}{l}\text { Almost no disease, } \\
\text { light loose disease }\end{array}$ & 94 \\
\hline
\end{tabular}

\footnotetext{
${ }^{1}$ PCI: Pavement Surface Condition Index.
} 

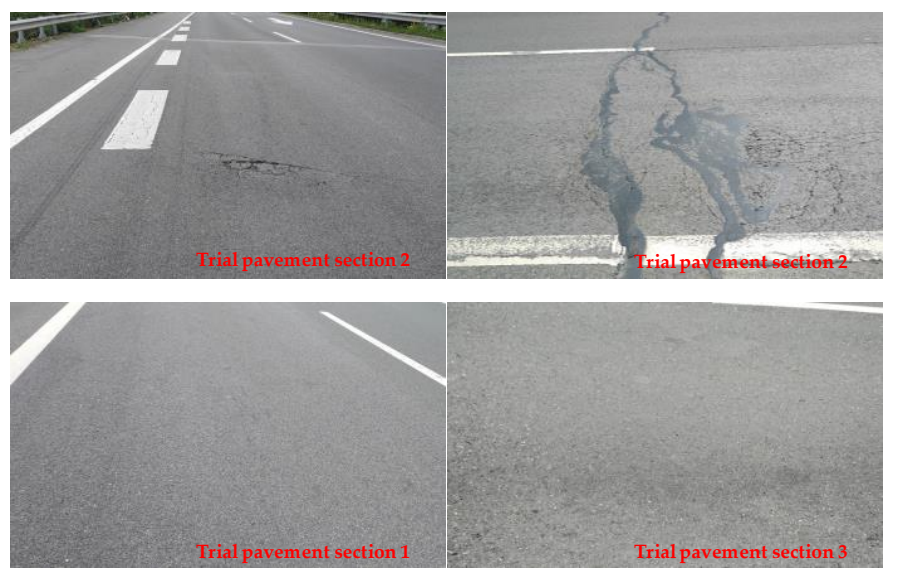

Figure 14. Representative disease photos of the trial sections.

According to the investigation results of the trial road, the disease degree of trial road 2 was the highest, and the Pavement Surface Condition Index (PCI) of trial road 2 in the third year was lower than that of trial road 3 in the UV zone II, and also lower than that of the trial road 1, which was in the UV radiation Zone I. However, trial section 3, with the anti-UV aging agent, and trial section 1, without the anti-UV aging agent, showed similar pavement performance. This shows that the equivalent performance of asphalt under different UV climate zones can be achieved through the previously discussed design.

Of course, limited by the number of trial roads, this conclusion still needs to be supported by a large number of engineering data.

\section{Conclusions}

Based on the average annual amount of UV radiation in China in the most recent 30 years and the characteristics of the UV aging of asphalt, the climatic zoning of UV radiation of asphalt in China was proposed. A variety of base asphalts and styrenebutadiene-styrene block copolymer (SBS) modified asphalts were selected to carry out the UV radiation test, and the relationship between UV radiation amount and viscosity, low-temperature performance, and rheological properties of asphalt were studied. The equivalent aging indexes of asphalt during UV radiation were selected, the UV aging equation of asphalt was proposed, and the equivalent UV aging relationship among different UV climate zones was established. The prevention and control strategies of UV aging of asphalt among different zones were proposed, and the above theory was verified using a trial road.

The main conclusions are shown as follows:

- The asphalt UV climate zone I is the area with annual UV radiation less than or equal to $69.4 \mathrm{~kW} \cdot \mathrm{h} / \mathrm{m}^{2}$ in the most recent 30 years, zone II is areas with annual UV radiation of $69.4 \sim 81.4 \mathrm{~kW} \cdot \mathrm{h} / \mathrm{m}^{2}$ in the most recent 30 years, and zone III is areas with annual UV radiation more than or equal to $81.4 \mathrm{~kW} \cdot \mathrm{h} / \mathrm{m}^{2}$ in the most recent 30 years;

- The greater the amount of UV radiation, the greater the loss rate of penetration and ductility. For the same kind of asphalt, there is a relatively stable functional relationship between the loss rate and the amount of UV radiation.

- For asphalt, the $\mathrm{G}^{*}$ increases and $\delta$ decreases with increasing UV aging time, which indicates that the elastic component of the asphalt response becomes more dominant and the viscous component less dominant with UV aging.

- The penetration loss rate and ductility loss rate of asphalt can be used as equivalent UV aging indexes of asphalt.

- Under the same outdoor UV irradiation time, if asphalt wants to achieve the same technical performance as in zone I, the anti-UV ability of zone II needs to be improved by more than $5 \%$, and that of zone III needs to be improved by more than $10 \%$. 
It is necessary to state that the aging of asphalt mixtures is not only directly connected with UV aging of the binder but also with its composition and with humidity variations; the aging progress is different within the different thicknesses of asphalt mixtures and this progress is not related just to the type of binder $[47,48]$. This paper intended to contribute to a more informed choice of the asphalt to use for surface courses constructed in different regions of China, by helping to address the aging issue on the asphalt mixtures themselves.

Author Contributions: Conceptualization, Z.L. and W.Z.; data curation, H.X. and W.Z.; funding acquisition, L.Z.; investigation, Z.L. and Y.C.; methodology, L.Z., M.L. and W.Z.; project administration, W.Z.; resources, W.Z.; software, H.X.; supervision, M.L.; writing-original draft, L.Z. All authors have read and agreed to the published version of the manuscript.

Funding: Please add: This research was funded by "National Key R\&D Program of China, grant number 2018YFB1600100", "Key Laboratory of Transport Industry of Road Structure and Material (Research Institute of Highway, Ministry of Transport), China, grant number 2019-Keji-271" and "Zhangdian District Science and Technology Bureau, China, grant number 9001-118232".

Institutional Review Board Statement: Not applicable.

Informed Consent Statement: Not applicable.

Data Availability Statement: The data presented in this study are available on request from the corresponding author. The data used to support the findings of this study are from previously reported studies, which have been cited. This manuscript does not contain previously published Figures, Tables, and Charts, so all Figures, Tables, and Charts of this manuscript are original.

Acknowledgments: We thank Nangxiang Zheng, Xiaoming Huang and Diancang Tai for the help in the experiment.

Conflicts of Interest: The authors declare no conflict of interest.

\section{References}

1. Yu, H.; Yao, D.; Qian, G.; Cai, J.; Gong, X.; Cheng, L. Effect of ultraviolet aging on dynamic mechanical properties of SBS modified asphalt mortar. Constr. Build. Mater. 2021, 281, 122328. [CrossRef]

2. Wang, L.; Cui, S.; Feng, L. Research on the influence of ultraviolet aging on the interfacial cracking characteristics of warm mix crumb rubber modified asphalt mortar. Constr. Build. Mater. 2021, 281, 122556. [CrossRef]

3. Cao, Z.; Huang, X.; Yu, J.; Han, X.; Wang, R.; Li, Y. Study on all-components regeneration of ultraviolet aged sbs modified asphalt for high-performance recycling. J. Clean. Prod. 2020, 276, 123376. [CrossRef]

4. Yue, M.; Yue, J.; Wang, R.; Xiong, Y. Evaluating the fatigue characteristics and healing potential of asphalt binder modified with sasobit and polymers using linear amplitude sweep test. Constr. Build. Mater. 2021, 289, 123054. [CrossRef]

5. Xu, X.; Guo, H.; Wang, X.; Zhang, M.; Wang, Z.; Yang, B. Physical properties and anti-aging characteristics of asphalt modified with nano-zinc oxide powder. Constr. Build. Mater. 2019, 224, 732-742. [CrossRef]

6. Sun, X.; Yuan, J.; Liu, Z.; Qin, X.; Yin, Y. Evaluation and characterization on the segregation and dispersion of anti-uv aging modifying agent in asphalt binder. Constr. Build. Mater. 2021, 289, 123204. [CrossRef]

7. Nciri, N.; Kim, J.; Kim, N.; Cho, N. An in-depth investigation into the physicochemical, thermal, microstructural, and rheological properties of petroleum and natural asphalts. Materials 2016, 9, 859. [CrossRef] [PubMed]

8. Ziari, H.; Akbari, T.; Goli, A. The effect of lucobit polymer on bitumen performance. Pet. Sci. Technol. 2016, 34, 512-516. [CrossRef]

9. Zhang, W.; Shi, J.; Jia, Z. The UV anti-aging performance of TPS modified bitumen. Pet. Sci. Technol. 2018, 36, 1164-1169. [CrossRef]

10. Shirzad, S.; Hassan, M.M.; Aguirre, M.A.; Mohammad, L.N.; Cooper, S.J.; Negulescu, I.I. Rheological properties of asphalt binder modified with recycled asphalt materials and light-activated self-healing polymers. Constr. Build. Mater. 2019, 220, 187-195. [CrossRef]

11. Zhang, H.; Chen, Z.; Xu, G.; Shi, C. Evaluation of aging behaviors of asphalt binders through different rheological indices. Fuel 2018, 221, 78-88. [CrossRef]

12. Fang, J.; Tu, J. Effect of ultraviolet (UV) aging on rheology properties and microstructure of polyurethane (PU) modified asphalt. Mater. Res. Express 2019, 6, 125318. [CrossRef]

13. Liu, J.; Liu, J.; Saboundjian, S. Evaluation of cracking susceptibility of alaskan polymer modified asphalt binders using chemical and rheological indices. Constr. Build. Mater. 2021, 271, 121897. [CrossRef]

14. Ravichandran, M.; Castorena, C. Critical evaluation of dynamic shear rheometer (DSR)-based methods to measure asphalt binder diffusion. J. Test. Eval. 2021, 50, 20200432. [CrossRef]

15. Walubita, L.F.; Gonzalez-Hernandez, J.G.; Martinez-Arguelles, G.; Tanvir, H.; Fuentes, L.; Tahami, S.A. Statistical Evaluation of the Material-Source Effects on the DSR Rheological Properties of Plant-Mix Extracted Asphalt-Binders. Materials 2021, 14, 1931. [CrossRef] [PubMed] 
16. Hossain, R.; Wasiuddin, N.M. Evaluation of degradation of sbs modified asphalt binder because of rtfo, pav, and uv aging using a novel extensional deformation test. Transp. Res. Rec. J. Transp. Res. Board 2019, 2673, 447-457. [CrossRef]

17. Niu, T.; Roque, R.; Lopp, G.A. Development of a binder fracture test to determine fracture energy properties. Road Mater. Pavement Des. 2014, 15, 219-238. [CrossRef]

18. Zhou, X.; Zhao, G.; Wu, S.; Tighe, S.; Pikel, D.; Chen, M.; Adhikari, S.; Gao, Y. Effects of biochar on the chemical changes and phase separation of bio-asphalt under different aging conditions—sciencedirect. J. Clean. Prod. 2020, 263, 121532. [CrossRef]

19. Hosseinnezhad, S.; Zadshir, M.; Yu, X.; Yin, H.; Sharma, B.K.; Fini, E. Differential effects of ultraviolet radiation and oxidative aging on bio-modified binders. Fuel 2019, 251, 45-56. [CrossRef]

20. Cui, B.; Gu, X.; Hu, D.; Dong, Q. A multiphysics evaluation of the rejuvenator effects on aged asphalt using molecular dynamics simulations. J. Clean. Prod. 2020, 259, 120629. [CrossRef]

21. Tan, Y.Q.; Wang, J.N.; Feng, Z.L.; Zhou, X.Y.; Xu, H.N. Ultraviolet aging mechanism of asphalt binder. China J. Highw. Transp. 2008, 21, 19-24.

22. Wei, C.; Duan, H.; Zhang, H.; Chen, Z. Influence of SBS modifier on aging behaviors of SBS-modified asphalt. J. Mater. Civ. Eng. 2019, 31, 04019184. [CrossRef]

23. Zhang, W.; Zhang, Y.X.; Jia, Z.; Wang, F.; Ding, L. Test method and material design of asphalt mixture with the function of photocatalytic decomposition of automobile exhaust. Constr. Build. Mater. 2019, 215, 298-309. [CrossRef]

24. Li, Y.; Wu, S.; Dai, Y.; Pang, L.; Liu, Q.; Nie, S.; Li, H.; Wang, Z. Laboratory and field evaluation of sodium stearate organically modified ldhs effect on the anti aging performance of asphalt mixtures. Constr. Build. Mater. 2018, 189, 366-374. [CrossRef]

25. Xue, Y.; Hu, Z.; Wang, C.; Xiao, Y. Evaluation of dissolved organic carbon released from aged asphalt binder in aqueous solution. Constr. Build. Mater. 2019, 218, 465-476. [CrossRef]

26. Sun, X.; Qin, X.; Liu, Z.; Yin, Y.; Zou, C.; Jiang, S. New preparation method of bitumen samples for UV aging behavior investigation. Constr. Build. Mater. 2020, 233, 117278. [CrossRef]

27. Li, L.; Guo, Z.; Ran, L.; Zhang, J. Study on low-temperature cracking performance of asphalt under heat and light together conditions. Materials 2020, 13, 1541. [CrossRef] [PubMed]

28. Wang, R.; Yue, J.; Li, R.; Sun, Y. Evaluation of aging resistance of asphalt binder modified with graphene oxide and carbon nanotubes. J. Mater. Civ. Eng. 2019, 31, 04019274. [CrossRef]

29. Osmari, P.H.; Leite, L.F.M.; Aragão, F.T.S.; Cravo, M.C.C.; Dantas, L.N.; Macedo, T.F. Cracking resistance evaluation of asphalt binders subjected to different laboratory and field aging conditions. Road Mater. Pavement Des. 2019, 20, 663-667. [CrossRef]

30. Liu, S.; Xu, Y.; Zhou, S. Evaluation of UV aging behaviors of polyphosphoric acid (ppa) modified asphalt and its asphalt mixture. Sci. Iran. 2020, 27, 2247-2257. [CrossRef]

31. Wang, D.; Falchetto, A.C.; Riccardi, C.; Westerhoff, J.; Wistuba, M.P. Investigation on the effect of physical hardening and aging temperature on low-temperature rheological properties of asphalt binder. Road Mater. Pavement Des. 2021, 22, 1117-1139. [CrossRef]

32. Feng, Z.; Song, X.; Sun, Y.; Yu, J. Performance evaluation of SBS modified asphalt with different anti-aging additives. J. Test. Eval. 2012, 40, 20120047. [CrossRef]

33. Xing, L.; Wu, S.; Gang, L.; Ma, S. Research on viscoelasticity of modified bitumen containing ldhs anti-uv aging agent. J. Wuhan Univ. Technol.-Mater. Sci. Ed. 2015, 30, 1321-1324. [CrossRef]

34. Li, H.; Yu, J.; Wu, S.; Pang, L.; Li, Y.; Wu, Y. Property of anti-ultraviolet aging of LDHs modified asphalt. J. Wuhan Univ. Technol.-Mater. Sci. Ed. 2018, 33, 634-638. [CrossRef]

35. Li, C.; Wu, S.; Chen, Z.; Shu, B.; Li, Y.; Xiao, Y.; Liu, Q. Synthesis of fe3o4-decorated mg-al layered double hydroxides magnetic nanosheets to improve anti-ultraviolet aging and microwave absorption properties used in asphalt materials. Constr. Build. Mater. 2019, 220, 320-328. [CrossRef]

36. Li, Y.; Wu, S.; Dai, Y.; Pang, L.; Liu, Q.; Xie, J.; Kong, D. Investigation of sodium stearate organically modified ldhs effect on the anti aging properties of asphalt binder. Constr. Build. Mater. 2018, 172, 509-518. [CrossRef]

37. Xie, X.; Hui, T.; Luo, Y.; Li, H.; Wang, Z. Research on the properties of low temperature and anti-UV of asphalt with nano$\mathrm{ZnO} /$ nano- $\mathrm{TiO}_{2} /$ copolymer SBS composite modified in high-altitude areas. Adv. Mater. Sci. Eng. 2020, 1-15. [CrossRef]

38. Yang, J.; Muhammad, Y.; Yang, C.; Liu, Y.; Li, J. Preparation of tio2/ps-rgo incorporated sbs modified asphalt with enhanced resistance against ultraviolet aging. Constr. Build. Mater. 2021, 276, 121461. [CrossRef]

39. Peng, C.; Yu, J.; Dai, J.; Yin, J. Effect of Zn/Al layered double hydroxide containing 2-hydroxy-4-n-octoxy-benzophenone on UV aging resistance of asphalt. Adv. Mater. Sci. Eng. 2015, 739831. [CrossRef]

40. Qian, G.; Yang, C.; Huang, H.; Gong, X.; Yu, H. Resistance to Ultraviolet Aging of Nano-SiO2 and Rubber Powder Compound Modified Asphalt. Materials 2020, 13, 5067. [CrossRef] [PubMed]

41. Zhang, Y.; Wei, H.; Dai, Y. Influence of different aging environments on rheological behavior and structural properties of rubber asphalt. Materials 2020, 13, 3376. [CrossRef] [PubMed]

42. CMA. China Wind and Solar Energy Resources Bulletin; CMA, Wind and Solar Energy Resources Center: Beijing, China, 2020.

43. Osgeo China Center. Available online: https://www.osgeo.cn/map/me31b (accessed on 22 January 2021).

44. Naskar, M.; Reddy, K.S.; Chaki, T.K.; Divya, M.K.; Deshpande, A.P. Effect of ageing on different modified bituminous binders: Comparison between RTFOT and radiation ageing. Mater. Struct. 2013, 46, 1227-1241. [CrossRef]

45. Zeng, W.; Wu, S.; Wen, J.; Chen, Z. The temperature effects in aging index of asphalt during UV aging process. Constr. Build. Mater. 2015, 93, 1125-1131. [CrossRef] 
46. The Ministry of Communications Highway Science Institute. Technical Specification of Construction of Highway Asphalt Pavements; JTG F40-2004; China Communications Press: Beijing, China, 2004.

47. João, C.; Luís, P.S.; José, N.; Silvino, C.; Imad, L.A.Q. Tecnico accelerated ageing (teage)—A new laboratory approach for bituminous mixture ageing simulation. Int. J. Pavement Eng. 2018, 21, 1-13. [CrossRef]

48. João Miguel Lopes, C.; de Luís Guilherme, P.S.; das José Manuel Coelho, N.; Silvino Dias, C. The teage ageing method for asphalt mixtures. Transp. Eng. 2020, 2, 100030. [CrossRef] 